Published in final edited form as:

Nat Rev Cardiol. 2014 February ; 11(2): 112-123. doi:10.1038/nrcardio.2013.196.

\title{
Endovascular treatment of abdominal aortic aneurysms
}

\author{
Dominique B. Buck, \\ Department of Vascular Surgery, University Medical Centre Utrecht, Heidelberglaan 100, 3584 \\ CX Utrecht, Netherlands \\ Division of Vascular and Endovascular Surgery, Beth Israel Deaconess Medical Centre, Harvard \\ Medical School, 110 Francis Street Suite B, Boston, MA 02215, USA \\ Joost A. van Herwaarden, \\ Department of Vascular Surgery, University Medical Centre Utrecht, Heidelberglaan 100, 3584 \\ CX Utrecht, Netherlands \\ Marc L. Schermerhorn, and \\ Division of Vascular and Endovascular Surgery, Beth Israel Deaconess Medical Centre, Harvard \\ Medical School, 110 Francis Street Suite B, Boston, MA 02215, USA \\ Frans L. Moll \\ Department of Vascular Surgery, University Medical Centre Utrecht, Heidelberglaan 100, 3584 \\ CX Utrecht, Netherlands
}

\begin{abstract}
Patients with abdominal aortic aneurysms (AAAs) are usually treated with endovascular aneurysm repair (EVAR), which has become the standard of care in many hospitals for patients with suitable anatomy. Clinical evidence indicates that EVAR is associated with superior perioperative outcomes and similar long-term survival compared with open repair. Since the randomized, controlled trials that provided this evidence were conducted, however, the stent graft technology for infrarenal AAA has been further developed. Improvements include profile downsizing, optimization of sealing and fixation, and the use of low porosity fabrics. In addition, imaging techniques have improved, enabling better preoperative planning, stent graft placement, and postoperative surveillance. Also in the past few years, fenestrated and branched stent grafts have increasingly been used to manage anatomically challenging aneurysms, and experiments with offlabel use of stent grafts have been performed to treat patients deemed unfit or unsuitable for other treatment strategies. Overall, the indications for endovascular management of AAA are expanding to include increasingly complex and anatomically challenging aneurysms. Ongoing studies and
\end{abstract}

Correspondence to: F. L. Moll f.1.moll@umcutrecht.nl.

Competing interests

J. A. van Herwaarden declares associations with the following companies: Medtronic and Philips. M. L. Schermerhorn declares associations with the following companies: Endologix and Medtronic. F. L. Moll declares associations with the following company: Medtronic. See the article online for full details of the relationships. D. B. Buck declares no competing interests.

Author contributions

D. B. Buck researched data for the article. D. B. Buck and J. A. van Herwaarden wrote the manuscript. All authors substantially contributed to discussion of content and reviewed and edited the manuscript before submission. 
optimization of imaging, in addition to technological refinement of stent grafts, will hopefully continue to broaden the utilization of EVAR.

\section{Introduction}

The concept of endovascular aneurysm repair (EVAR) was first reported by Volodos et al. ${ }^{1,2}$ in 1986 and by Parodi and colleagues in $1991 .{ }^{3}$ Since that time, EVAR has become widely accepted as a safe technique for the treatment of abdominal aortic aneurysm (AAA). ${ }^{4}$ Early application of the endovascular technique was for the treatment of old patients with substantial comorbid illness who were unfit for open repair. However, the indications for this minimally invasive technique have expanded considerably since the procedure was first used. By 2003, EVAR was used for nearly half of all elective AAA repairs in the USA. ${ }^{6}$ Currently, the majority of patients with anatomically suitable infrarenal AAA are treated with EVAR, rather than with open repair. ${ }^{7}$ Indeed, a retrospective analysis of Medicare beneficiaries undergoing AAA repair in the USA showed that EVAR accounted for $77 \%$ of intact AAA repairs in $2008 .^{8}$

In this Review, we provide both a contemporary reappraisal of evidence-based practice and an evaluation of promising new strategies in the endovascular management of AAAs. The role of imaging in the management of AAA, as well as new, innovative techniques and offlabel use of stent grafts are discussed. This Review has a particular focus on indications for intervention and operative technique for patients who are anatomically unsuitable for standard EVAR. Treatment of patients with juxtarenal or suprarenal aneurysms is covered, and an overview of the premise of the evolving nature of endovascular surgery is provided.

\section{Incidence of AAA}

The risk factors for AAA have been well described and include advanced age, cardiovascular disease, family history of AAA, smoking, and male sex. ${ }^{9-11}$ Although the incidence of AAA is fourfold higher in men than in women, AAA rupture occurs at smaller aortic diameters in women, and they present for care at a more-advanced age than men. ${ }^{12}$ Moreover, large-scale studies of females with AAA have demonstrated poorer outcomes than those experienced by men. ${ }^{12-14}$ These findings indicate a difference in the natural history of disease between men and women.

In the 1980s and 1990s, an increase in overall AAA mortality was observed. ${ }^{15-18}$ However, epidemiological reports from the 2000s have shown the incidence of AAA in developed countries to be decreasing. ${ }^{19,20}$ Moreover, in an American study of 338,278 Medicare beneficiaries undergoing AAA repair from 1995 to 2008, the total number of AAA ruptures decreased from 6,535 to 3,298 over the study period, yet the proportion of ruptures undergoing repair changed only slightly (from $70 \%$ to $65 \%$ ). ${ }^{8}$ Interestingly, the overall number of annual deaths from both intact and ruptured AAAs has decreased significantly since the introduction of EVAR. ${ }^{8,21}$ This reduction in ruptured AAA has been multifactorial, with valuable contributions made by improved screening programmes, decreased prevalence of smoking, improved cardiovascular risk prevention, and an increase in elective surgery in patients aged $>75$ years. ${ }^{22,23}$ 


\section{Imaging in AAA management}

Imaging has a very important role in the management of AAA. Several modalities are available for clinicians assessing patients with this condition.

\section{Ultrasonography}

The most-commonly used technique for screening and surveillance of patients with AAA is ultrasonography (Figure 1a,b). This imaging modality has a high sensitivity and specificity, is inexpensive and noninvasive, and does not subject the patient to ionizing radiation. ${ }^{24,25}$ The disadvantages of this technique are that it is operator-dependent and provides lessaccurate diameter measurements than other available imaging modalities. Therefore, unlike computed tomography angiography (CTA; discussed below), ultrasonography is not suitable for use in preoperative work-up for AAA surgery. ${ }^{26}$ Ultrasonography is mainly used for monitoring aneurysm growth and discovering postoperative endoleaks. ${ }^{27}$ Contrast-enhanced ultrasonography, which involves the use of microbubble contrast agents, can be used safely in patients with impaired renal function. This imaging modality has been investigated as an alternative to CTA in the surveillance of patients after EVAR, and seems to provide accurate diagnostic information. ${ }^{28-30}$

\section{CTA}

Whereas conventional angiography has largely fallen out of favour as a first-line imaging modality in the management of AAA, spiral CTA, with its less-invasive approach, has been demonstrated to be the best imaging technique for both preoperative patient assessment and postoperative aortic stent graft surveillance. ${ }^{31,32}$ The disadvantages of CTA are the radiation burden and the use of potentially nephrotoxic contrast agents. ${ }^{26}$ Nevertheless, CTA is fast and provides all necessary detailed anatomic information, including 3D visualization (Figure $1 \mathrm{c}, \mathrm{d}){ }^{33-35}$ 3D CTA currently also provides dynamic image capability, known as timeresolved or 4D CTA. These dynamic images can be used to assess variations in aortic diameter related to the pulsatile nature of the cardiac cycle. The critical nature of this variation was demonstrated in 2009 by Van Keulen and colleagues, who concluded in their systematic review that the proximal stent-graft-landing zone (AAA neck diameter) differs significantly in systole and diastole. ${ }^{36}$

MRA

Magnetic resonance angiography (MRA) is another tool at the disposal of the vascular surgeon for pre operative assessment of patients with AAA (Figure 1e,f). Benefits of MRA include high-resolution soft-tissue contrast, and possible demonstration of arterial wall movement and flow quantification. In addition, MRA can be used to evaluate both the vascular lumen and its wall. ${ }^{37}$ Unlike CTA, MRA is obtained without the use of iodinated contrast material or radiation. ${ }^{38}$ Furthermore, MRA has higher sensitivity than CTA for the detection of endoleaks in patients after EVAR, particularly type 2 endoleaks. ${ }^{39}$ However, MRA is more expensive and more time consuming than CTA, does not visualize calcium as well as CTA, and is less comfortable than CTA for the patient (indeed, this modality is contraindicated in patients with claustrophobia or certain metallic implantations). Like CTA, MRA can generate dynamic images. Dynamic, time-resolved MRAs were first described in 
$1996,{ }^{40}$ and can be used to detect changes in vascular flow direction over time. The 4D MRA images are considered to be of most value in identifying endoleaks, as the inflow and outflow source can be well observed. ${ }^{40-42}$

IVUS

Intravascular ultrasound (IVUS; Figure 1g,h) is also a part of the imaging armamentarium of the vascular surgeon, providing a $360^{\circ}$ cross-sectional view of the vessel being evaluated. Maximum aortic diameter, varying with the cardiac cycle, can be evaluated in real time. IVUS can also be used to limit contrast administration in patients with renal insufficiency, as this technique is occasionally used as an adjunct without contrast injection. Despite these advantages, IVUS is susceptible to operator-dependent error, as accurate measurements require centring of the probe within the lumen, a task that becomes increasingly difficult with larger aortic diameter and longer procedure duration. Moreover, IVUS requires percutaneous vascular access, unlike noninvasive MRA or CTA. IVUS is currently primarily used for research purposes. ${ }^{43,44}$

\section{Clinical evidence for benefits of EVAR}

Comparison of EVAR with open surgical repair of AAA has been the subject of several well-designed randomized, controlled trials as well as various observational studies of the 'real world' setting.

\section{Randomized, controlled trials}

Accruing 351 patients between 2000 and 2003, the DREAM (Dutch Randomized Endovascular Aneurysm Management) trial demonstrated 30-day mortality of 1.2\% and $4.6 \%$ for EVAR and open repair, respectively $(P=0.10) .{ }^{45}$ Additionally, the EVAR cohort was found to have a shorter hospital stay than the cohort who underwent open repair (6 days versus 13 days, $P<0.001$ ) and lower incidence of moderate or severe systemic complications over 30 days $(11.7 \%$ versus $26.4 \%, P<0.001) .{ }^{45}$ The study showed a combined rate of severe complications and operative mortality of $4.7 \%$ for the EVAR group compared with $9.8 \%$ for the open-repair group $(P=0.10) .{ }^{45}$ Of note, however, subsequent longer-term follow up of this trial revealed that the perioperative survival advantage of EVAR over open repair was not sustained after the first postoperative year. ${ }^{46}$ After 6 years of follow-up, the rates of survival remained similar in the EVAR and open-repair groups (68.9\% and 69.9\%, respectively).$^{47}$ Additionally, the long-term rates of secondary interventions were significantly higher for EVAR than for open repair over the 6-year follow-up period $(29.6 \%$ versus $18.1 \%, P=0.03) .{ }^{47}$ The most-common secondary interventions in the EVAR group were stent-graft-related interventions, whereas the mostcommon procedure in the open-repair group was abdominal incisional hernia repair. ${ }^{47}$

The UK EVAR 1 (UK Endovascular Aneurysm Repair 1) trial, ${ }^{48}$ involving 1,082 patients treated between 1999 and 2003, also demonstrated a clear short-term survival benefit for EVAR compared with open surgery. Among patients who were candidates for either EVAR or open repair, EVAR was associated with lower rates of 30-day operative mortality than open repair $(1.7 \%$ versus $4.7 \%, P=0.009) .{ }^{48}$ Median operative time ( 180 min versus 200 
min, $P<0.0001)$ and length of hospital stay ( 7 days versus 12 days, $P<0.0001)$ were also lower in the EVAR group. ${ }^{48}$ Perioperative mortality was lower with EVAR, ${ }^{48}$ and lower disease-specific mortality was noted in the EVAR group at the 4-year follow-up (4\% versus $7 \%$ in the open-repair group, $P=0.04$ ); however, at the 4-year follow-up, no difference in all-cause mortality ( $26 \%$ versus $29 \%, P=0.46$ ) was observed between the two groups. ${ }^{49}$ Moreover, the early aneurysm-related mortality benefit with EVAR was counteracted by higher aneurysm-related mortality in the EVAR group than the open repair group after 4 years $(2.1 \%$ versus $0.4 \%, P=0.05$, in patients followed up for $4-8$ years $) .{ }^{50}$ The lack of difference in all-cause mortality persisted throughout the 8 years of follow up. ${ }^{50}$

Additionally, cost analyses showed higher costs for the EVAR group (mean costs $£ 15,303$ versus $£ 12,284$ for open-repair), and a greater number of secondary interventions occurred in the EVAR group than in the open-repair group $(5.1 \%$ versus $1.7 \%, P<0.001)$ over the long-term follow-up period. ${ }^{50}$

The UK EVAR 2 trial investigators compared survival in patients unfit for open repair $(n=$ 338 ) who were randomly assigned to either EVAR or no intervention. ${ }^{51-53}$ Of note, the randomization in both the UK EVAR trials was determined by the surgeon at the local level. The EVAR 2 trial did not demonstrate a survival benefit for elective EVAR compared with no intervention in this frail patient population. ${ }^{51-53}$ However, notably, both UK EVAR trials were based on intention-to-treat analysis, with significant patient crossover between groups allowing for potentially biased results. In EVAR 2, more than one-quarter of patients assigned to no intervention for their aneurysm underwent aneurysm repair, of which $30 \%$ received surgery because of patient preference. ${ }^{51,53}$ This limitation and the lengthy delay between randomization and surgery in EVAR 2 (median 51 days ${ }^{51}$ ) have made it challenging for clinicians to accept the conclusion that EVAR is not worthwhile in high-risk patients.

The USA OVER (USA Open Versus Endovascular Repair) trial investigators assigned 881 patients to either EVAR or open repair between 2002 and 2008. ${ }^{54}$ This multicentre, randomized trial showed a significant peri-operative benefit for EVAR, with lower mortality in the EVAR group than in the open-repair group at 30 days $(0.5 \%$ versus $3.0 \%, P=0.004)$ as well as a shorter operative time ( $2.9 \mathrm{~h}$ versus $3.7 \mathrm{~h}, P<0.001)$ and length of hospital stay ( 3 days versus 7 days, $P<0.001$ ) for the EVAR group. ${ }^{54}$ However, EVAR did not confer a survival benefit at the 2-year follow-up (mortality $7.0 \%$ versus $9.8 \%$ for open repair, $P=$ 0.13). ${ }^{54}$ Furthermore, rates of other outcomes also converged by longer-term follow-up: no differences were observed at 2 years in quality of life or secondary therapeutic procedures. ${ }^{54}$ Although the study population generally demonstrated similar long-term outcomes at the most-recent follow-up reported (up to 9 years; mean 5.2 years), ${ }^{55}$ subgroup analysis did show significantly increased long-term survival for patients aged $<70$ years undergoing EVAR compared with those assigned to open repair (HR $0.65,95 \%$ CI $0.43-0.98, P=$ $0.04) .55$

From 2003 to 2008, the French ACE (Anevrysme de l'aorta abdominale, Chirurgie versus Endoprothese) investigators randomly assigned 316 patients to EVAR or open surgery. ${ }^{56}$ No difference in survival was observed between the two patient groups at a median of follow-up of 3 years (EVAR $11.3 \%$ versus open repair $8 \%, P=\mathrm{NS}$ ). ${ }^{56}$ However, significant 
differences were seen with respect to long-term vascular reintervention rates (EVAR 16\% versus open repair $2.7 \%, P<0.0001) .{ }^{56}$ Like the UK EVAR 1 and 2 trials, this study followed an intention-to-treat analysis with apparent cross-over between study groups. ${ }^{56}$

\section{Observational studies}

To understand the comparative effectiveness of various interventions, inquiry should be extended beyond randomized, controlled trials of ideal populations to study interventions in 'real world' settings using observational data. Although observational studies that rely on administrative data are subject to coding errors, they provide invaluable data about 'real world' outcomes outside of the tightly controlled parameters of randomized, controlled trials.

In 2008, Schermerhorn and colleagues studied a cohort of 61,598 Medicare beneficiaries undergoing open or endovascular repair in the USA from 2001 to $2004 .{ }^{57}$ EVAR was associated with lower rates of perioperative death $(1.2 \%$ versus $4.8 \%, P<0.001)$ and various major medical and surgical complications than open repair. ${ }^{57}$ The early benefit from endovascular repair persisted for more than 3 years, after which the survival rates associated with the two procedures converged ${ }^{57}$ The lower early mortality with EVAR was more apparent with increasing age; for patients aged $\geq 85$ years, the difference in mortality between the two groups was $8.5 \%$, whereas the difference was $2.1 \%$ for patients aged $67-69$ years. ${ }^{57}$ This observational study was the first to look at a broad set of procedure-related interventions. Although patients who underwent EVAR were more likely to undergo AAArelated interventions during a 4-year follow-up period (9.0\% versus $1.7 \%$ with open repair, $P<0.001$ ), this finding was partially offset by a reduced likelihood of hospitalizations without surgery for a diagnosis of bowel obstruction or abdominal-wall hernia $(8.1 \%$ versus $14.2 \%, P<0.001)$ and laparotomy-related interventions $(4.1 \%$ versus $9.7 \%, P<0.001) .{ }^{57} \mathrm{As}$ in prior studies, EVAR was associated with a shorter length of stay than open repair (3.4 days versus 9.3 days, $P<0.001)$ in this large observational study. ${ }^{57}$ Owing to the selection of patients aged $>65$ years, the cohort might not be representative of the general population; however, the size of the study probably overcomes any selection bias. Importantly, the results were comparable to the randomized, controlled trials discussed above, demonstrating that the findings from these aforementioned randomized trials can be generalized.

In 2011, Schanzer et al. reported their findings from a study of CTA scans of 10,228 patients who underwent EVAR for AAA from 1999 to 2008 and were included in the M2S, Inc. database. ${ }^{58}$ This retrospective observational study showed a $41 \%$ incidence of sac enlargement 5 years after EVAR, a rate that increased over time. ${ }^{58}$ The rate of sac enlargement was significantly increased in patients who underwent EVAR from 2004 to 2008 compared with patients who underwent EVAR between 1999 and 2003. ${ }^{58}$ The overall incidence of any endoleak was $32 \%$, with the majority manifesting during the first postoperative year after EVAR. ${ }^{58}$ In a letter to the Editor of Circulation, however, Mark Fillinger explained that the M2S, Inc. database is not a consecutive, observational series, and that a large percentage of patients with normal anatomy is purposely excluded. ${ }^{59} \mathrm{In}$ most cases, postoperative CT scans are only submitted to M2S, Inc. when the aneurysm is not shrinking, which leads to a selection bias with limited available follow-up data. As the study 
investigators had access to measurements, but not to the CT images, the evaluation of the primary pathology is questionable. In addition, sac expansion was not calculated from the first postoperative $\mathrm{CT}$, which inflates the expansion rate relative to standard reporting methods.

\section{Procedural improvements over time}

The studies discussed above were conducted over the past 10 years and include the largest, most-cutting-edge trials performed to date. Notably, however, the findings related to outcomes after EVAR have improved over time. Indeed, for the most-recent trial with detailed follow-up - the USA OVER trial—investigators reported low mortality and low reintervention rates, confirming continued improvement of EVAR.

Endovascular device technology has been subject to strenuous research and development efforts over the past 20 years. Since the aforementioned studies were undertaken, a number of stent grafts have been developed and improved. Imaging technology has also improved over time, with resultant improvement in patient assessment. Preoperative CTA scanning has evolved to enable thinner slices, improving the accuracy of measurements, and the development of 3D software packages has made measuring and planning of EVAR easier. In addition, the fluoroscopy equipment used for EVAR has improved over time. In many hospitals, mobile C-arms are replaced by fixed X-ray systems in hybrid operating rooms, which provide better image quality. Additionally, physicians themselves have gained experience and revised their criteria for identifying suitable candidates for EVAR. These improvements have likely led to better outcomes now compared with $>10$ years ago.

The clinical evidence accrued thus far gives an insight into surgical outcome rates; however, a number of unsolved issues remain. As the endovascular technique continues to improve, problems related to endoleaks, late device failures, life-long imaging, and late rupture risk must continue to be optimized.

All the factors discussed above contribute to the evolving nature of endovascular surgery. This evolution necessitates continued research to evaluate outcomes on an ongoing basis.

\section{Indications for EVAR}

The required anatomical criteria listed in the manufacturers' instructions for use for commercially available AAA endovascular devices approved by the FDA are shown in Table $1 .{ }^{12,60} \mathrm{~A}$ commonly used definition of AAA is a maximum aortic diameter of $3 \mathrm{~cm}$. For aneurysms $<5 \mathrm{~cm}$, a surgical intervention is not indicated; however, the patient should be kept under surveillance. In Europe, as well as in the USA, an aneurysm diameter of $\geq 5$ $\mathrm{cm}$ is generally considered an indication for aneurysm repair, ${ }^{26}$ although early surgical repair of aneurysms $<5.5 \mathrm{~cm}$ has been shown to offer no advantage over surveillance. ${ }^{61}$ As discussed above, AAAs rupture at smaller diameters in women than in men and, therefore, women might benefit from early treatment. ${ }^{12}$

The proportion of patients treated with EVAR has increased over time, with an estimated $77 \%$ of intact AAA repairs being undertaken via EVAR in the USA in $2008 .{ }^{8}$ The 
manufacturers' instructions for use for most stent grafts have not changed greatly in the past decade, but many other factors might contribute to the increased use of EVAR: diffusion of new technology from high-volume, early adopting centres to more-remote, lower-volume centres; increased operator experience with the capabilities and limitations of the technology; changing referral patterns; lower-profile and more-flexible devices allowing treatment through small or tortuous iliac arteries; and more-frequent treatment of patients who do not have anatomical criteria deemed appropriate for the procedure in the manufacturers' instructions for use.

\section{New devices and future developments}

As EVAR became widely accepted as a safe technique, some physicians began experimenting with off-label use of stent grafts to treat patients deemed unfit for open surgery, but who were also not candidates for standard EVAR. In line with this experimentation, several manufacturers have developed new stent graft systems thatalthough their effectiveness is not yet proven - might enable expansion of EVAR technology to many of those AAAs that are not anatomically suitable for current endografts with proven efficacy. Other devices have been developed in an attempt to improve outcomes in patients undergoing the procedure. Some of the new stent graft systems and devices are currently used widely, and others are associated with fewer evidence-based data and have not yet achieved broad utilization.

Many approaches to treating aortic aneurysms exist, and a wide variety of devices are available. No clear evidence supports one specific treatment regimen over another and, therefore, specific practice patterns vary between institutions. Our approach is to treat patients with sufficient proximal landing zone at the aortic neck with EVAR in a traditional fashion, using a stent graft of the surgeon's choosing. For patients with anatomy that does not provide an infrarenal aortic neck for fixation and sealing of a traditional stent graft, the next step depends on the suitability of the patient for open repair and the urgency of the clinical situation. Patients who elect to undergo AAA repair can be treated with an FDAapproved fenestrated or branched stent graft (described below), and emergent cases might be considered for management with off-label use of chimney or sandwich techniques (also described below). If the aortic diameter is large at the level of the target vessels, a branched stent graft can be used. As increasingly complex aortic pathology is treated via endovascular means, innovation has been driven through the use of novel techniques and devices customized in consultation with manufacturers. The surgeon must be judicious in the utilization of novel techniques outside the manufacturers' instructions for use, to ensure that they are employed with the utmost regard for patient safety.

The systems and devices discussed below are divided into those that have been approved by the FDA to be used safely, and those that have been more-recently developed and are in need of further research before device approval. These devices and techniques require advanced endovascular skills and have not been evaluated on a large scale. Although early reports support the use of these techniques in selected patients, limited data are available on their long-term use, and open repair remains the treatment choice in suitable candidates. However, within the setting of a clinical trial, in the hands of experienced physicians 
investigating promising devices, or for patients who could not otherwise be treated, some of the alternative techniques described below might be considered.

\section{New devices approved by the FDA \\ Endostapling}

In response to concerns about EVAR treatment failure secondary to endoleak and stent graft migration, endostaplers (Figure 2) have been developed to improve durability of the graft by fixation of the graft at its landing zones, and ultimately decrease the need for reintervention. In a prospective, single-centre study published in 2008 , the feasibility of endostapler use was evaluated, and 20 of 29 endostaples were found to have been placed successfully. ${ }^{62}$ Failures occurred in the setting of heavy vessel calcification, where the stapler failed to penetrate the tissue and retracted into the delivery device. In a midterm report published 2 years after the initial analysis, the investigators reported no device failures, migrations, endoleaks, conversions, or secondary procedures during follow-up (mean 18.2 months). ${ }^{63}$ In a morerecent study of 11 patients with primary stent graft failure secondary to distal stent migration, use of a similar device, called an 'endoanchor', with or without additional extender cuffs, resulted in no recurrent migration over a mean 10 months of follow-up, although two patients did require reintervention for persistent endoleaks. ${ }^{64}$ Overall, early studies have demonstrated endostapler technology to be safe and feasible for primary fixation of stent grafts or management of stent migration. The device received FDA approval in 2011.

\section{Fenestrated stent grafts}

Although EVAR has become the most-commonly performed treatment for patients with infrarenal AAA, a considerable number of patients with AAA (15-20\%) have moreproximal aneurysms, including in juxtarenal or suprarenal positions. ${ }^{65,66}$ EVAR was not previously considered a treatment option for patients with these challenging aneurysm configurations, because of the absence of a sufficient infrarenal neck for stent graft implantation. This problem was overcome through the introduction of the first fenestrated and branched stent grafts in 1999. ${ }^{67-69}$ Since then, technology in this area has advanced rapidly, and fenestrated stent grafts were granted FDA approval in $2012 .{ }^{60}$ Fenestrated grafts are now available for use above the renal arteries (Figure 3), with technology available for customization at the level of the individual patient.

Compared with repair of infrarenal AAA, open repair of juxtarenal AAA is characterized by more-extensive visceral mobilization to achieve adequate exposure of the abdominal aorta. This requirement can lead to prolonged suprarenal aortic clamping and the need for visceral vessel revascularization. Accordingly, a prolonged period of renal ischaemia can result from open repair of juxtarenal AAA, with an associated risk of postoperative acute kidney injury and even dependence on dialysis. ${ }^{66}$ Through a similar mechanism, bowel ischaemia secondary to temporary occlusion of the superior mesenteric artery can also occur in this setting, resulting in catastrophic complications such as multiorgan failure and death. ${ }^{70,71} \mathrm{In}$ a 2010 meta-analysis that included 21 studies of patients undergoing open repair of 
nonruptured juxtarenal AAA, the pooled perioperative mortality was $2.9 \%$ and the rate of new-onset haemodialysis was $3.3 \%{ }^{66}$

Fenestrated endovascular repairs have been shown to compare favourably to open surgery, with low operative morbidity and mortality ${ }^{72}$ In early reports of the use of fenestrated and branched stent grafts, patency rates of the visceral or renal arteries were approximately $95 \% .^{73-75}$ In a study of 650 patients undergoing branched or fenestrated AAA repair, longterm durability was favourable, with $89 \%$ freedom from secondary intervention at the 3-year follow-up. ${ }^{76}$ Subsequent smaller studies and reviews of the literature have further demonstrated these benefits. In a multicentre study of 134 patients treated with fenestrated stent grafts from 2004 to 2009,30 -day mortality was $2 \%$ and mortality during a median follow-up of 15 months was $9 \% .{ }^{77}$ No ruptured aneurysms were reported. ${ }^{77}$ In another study of 100 patients with short-necked or juxtarenal AAA, who were treated with fenestrated EVAR from 2001 to 2009, 30-day mortality was $1 \%$ and, again, no ruptured aneurysms were reported. ${ }^{78}$ A 2012 systematic review that included nine observational studies involving 629 patients demonstrated that EVAR using fenestrated stent grafts was associated with low 30-day mortality $(2.1 \%) .{ }^{79}$ In this analysis, the pooled estimates for branch-vessel patency, technical success, and reinterventions at a mean follow-up of 15-25 months were $93.2 \%, 90.4 \%$, and $17.8 \%$, respectively. ${ }^{79}$

Compared with standard EVAR, a disadvantage of EVAR using fenestrated stent grafts is that these grafts often require a high degree of customization, which increases cost and makes the technique prohibitively expensive for emergent cases. In addition, technical considerations such as severely angulated necks, aortic thrombus in the area of target vessels, and small, calcified target vessels might also prohibit the use of fenestrated grafts. Despite these limitations, fenestrated and branched stent grafts have increased the applicability of EVAR to patients who would otherwise be subject to highly morbid openrepair procedures.

According to a study involving 26 consulting physicians located across the UK, who reviewed 192 cases of EVAR using fenestrated stent grafts, consensus on indications for EVAR using fenestrated stent grafts occurs in almost $70 \%$ of cases. ${ }^{80}$ The reviewing physicians agreed on suitability for EVAR using fenestrated stent grafts in areas considered to be associated with moderate risk from open repair and the need for suprarenal clamping. EVAR using fenestrated stent grafts was, on the other hand, less likely to be considered indicated in patients aged $\geq 85$ years with aneurysms $\$ 6 \mathrm{~cm}$ and in cases with short-necked infrarenal aortic aneurysms. ${ }^{80}$ Ideally, a prospective, randomized, controlled trial comparing EVAR using fenestrated stent grafts with open repair should be performed.

\section{Devices and techniques not yet FDA approved}

\section{The chimney technique}

An alternative to the fenestrated stent graft for patients with challenging anatomy is the chimney graft (Figure 4), which also preserves the renal and/or mesenteric perfusion. The chimney graft is cheaper than the fenestrated stent graft, and has broader applicability for emergent cases because of the lack of need for customization. ${ }^{81,82}$ Similarly, patients 
ineligible for EVAR using fenestrated stent grafts because of anatomic exclusion criteria can potentially be treated with a chimney graft. Covered or uncovered chimney stent grafts can be deployed via brachial or axillary access while aortic stent grafts are deployed via traditional femoral access. ${ }^{83}$

A systematic review involving data for 75 patients who had undergone EVAR using a chimney procedure (96 chimney grafts used) demonstrated a technical success rate of $98.9 \%$, although operative techniques varied considerably between studies ${ }^{84}$ During followup that ranged from 2 days to 54 months, three deaths occurred as late complications and three chimney grafts occluded, necessitating two reinterventions. ${ }^{84}$ Long-term follow-up is not yet available, and FDA approval and CE mark have not yet been attained. However, the chimney procedure might one day offer an acceptable endovascular treatment option for patients with juxtarenal or suprarenal AAA, particularly those who are unfit for open surgery in an emergency setting or when fenestrated grafts are unavailable. ${ }^{81,82,84-86}$

\section{The sandwich technique}

The sandwich technique involves the use of stents placed in the aortic branches, like chimneys, that are 'sandwiched' between two aortic stent grafts (Figure 5a). ${ }^{87-89}$ This configuration permits a stable position of coaxial grafts between two aortic stents and is an attractive alternative for patients with anatomy not amenable to conventional EVAR. The technique allows the revascularization of up to four side branches, as opposed to the two permitted by the chimney technique. Notably, however, the revascularization of four side branches using a double two-chimney approach (Figure 5b) has been reported in the past few years. ${ }^{89,90}$ Although long-term outcomes are not yet available for either the sandwich technique or the double two-chimney approach, and these strategies are performed off-label, they hold potential for patients with difficult anatomy, especially given that they do not require customization. Notably, however, these techniques have only been used in situations not listed in the manufacturers' instructions for use.

\section{Off-the-shelf fenestrated stent grafts}

Currently, fenestrated and branched stent grafts must be customized for individual patients, a process that requires meticulous preoperative planning. Such customization can lead to substantial treatment delay, with risk of rupture in the intervening period. Such delays preclude the use of the technology in the acute setting. To allow more patients to be treated in the acute setting, standard off-the-shelf fenestrated and branched (Figure 6) stent grafts have been developed for treatment of patients with complex AAA. The T-branch stent graft is an off-the-shelf device that can be used for thoracoabdominal AAA treatment, whereas the P-branch off-the-shelf device can be used for aneurysms that limit just below the superior mesenteric artery.

During the period 2008-2010, Chuter et al. studied 28 patients who underwent AAA repair using custom-made or standard off-the-shelf fenestrated stent grafts $(n=14$ for each group) ${ }^{91}$ No cases of stent migration, aneurysm dilatation, rupture, or perioperative death were reported for either group. ${ }^{91}$ In another study conducted by Kitagawa and colleagues, ${ }^{92}$ 16 patients were recruited in 2011-2012 for treatment with an off-the-shelf P-branch device. 
The treatment was technically successful in all patients, taking into consideration that one patient had an occluded renal artery during follow-up, which was successfully recanalized. ${ }^{92}$ In 2012, Resch et al. reported on the successful treatment of seven patients with juxtarenal and suprarenal aneurysms using fenestrated off-the-shelf devices; no deaths and no endoleaks occurred during the 30-day follow-up period. ${ }^{93}$

Off-the-shelf fenestrated and branched stent grafts have the potential to reduce the need for preoperative graft customization and might be a solution for patients with AAA not suitable for traditional EVAR, particularly in the emergent setting. As limited clinical evidence is currently available, however, more research is needed before widespread implementation of this technique.

\section{Multilayer stent}

For management of complex aneurysms involving aortic branches, a new multilayer selfexpanding stent technology (Figure 7) has been developed. The technology has flowdiverting capabilities that can exclude the aneurysm while preserving collateral circulation via a series of interconnected, braided layers. Similar to the flow dynamics seen in saccular aneurysms with clinically relevant thrombosis, turbulent flow through the thrombotic segment creates a pressure gradient such that flow is drawn into the aortic branch. In a similar fashion, this multilayered stent graft could achieve diversion of flow into the vital visceral branches involved. Given that this technology has been developed over the past 5 years, however, little is known about its reliability and effectivness. ${ }^{94-96}$ In 2012, a systematic review involving data from 12 reports of patients ( $n=35 ; 38$ aneurysms) treated with flow-diverting stents was published; three of these patients had been treated for AAA.${ }^{96}$ Each of these three cases achieved technical success in stent deployment, aneurysm thrombosis and shrinkage, and patency of branch vessels. ${ }^{96}$ Further investigation for flowdiverting stents in the use of AAA management is ongoing. Although this off-the-shelf stent might potentially be used in patients with AAA not amenable to treatment via other previously described endovascular or open methods, the technique has not undergone the rigors of clinical testing and the effectiveness remains to be proven.

\section{A sac-anchoring endoprosthesis}

Unlike open AAA repair, EVAR leaves the aneurysm sac itself untreated, which allows the possibility of persistent blood flow (type 2 endoleak) and stent migration. The sac-anchoring endoprosthesis (Figure 8) is an endoluminal device that eliminates the endoleak space via obliteration of the aneurysm sac. This technology utilizes two femorally inserted stent grafts with polymer-filled endobags on the outside of the stents. The polymer-filled endobags enlarge to a pressure preset to support the stents within the aneurysm sac. Such technology might be employed in the setting of an infrarenal AAA with adverse anatomic features. ${ }^{97,98}$ In a prospective clinical trial published in 2011, perioperative aneurysm-related mortality was $2.9 \%$ among 34 patients undergoing AAA with sac anchoring. ${ }^{98}$ One patient had a secondary procedure because of an endoleak. CT surveillance for $>2$ years revealed no change in aneurysm size, no new endoleaks, and no change in stent graft position. ${ }^{98}$ The sac-anchoring endoprosthesis has been available in Europe since 2012, but is still awaiting FDA approval. 


\section{Other changes to stent graft design}

Developments in stent grafts have facilitated their deployment through smaller access sites than was previously possible, and with improved sealing and fixation in an ever-increasing cohort of patients. In addition, fabrics with reduced porosity have been developed to enable a rapid reduction in aneurysm size. ${ }^{99}$ Reduced stent graft profile and other improvements have thus far been achieved without adversely impacting the durability and sustainability of the stent graft itself. ${ }^{100}$ Low-profile stents with a delivery system diameter of 14 French have received CE Mark approval. To optimize sealing and fixation, low-profile stent graft systems have been designed with the use of transmural fixation with endoanchors, ${ }^{101,102}$ or with polymer-filled sealing rings, ${ }^{100}$ to improve stability in placement. Also, single lowprofile introducer sheaths combined with a thin-walled, low-porosity fabric have been developed to reduce aneurysm size. ${ }^{103}$

\section{Conclusions}

Over the past 20 years, endovascular technology has propelled EVAR from an obscure technology with limited applicability to being the standard of care in an increasing number of AAA indications. EVAR utilization has broadened so dramatically that up to $77 \%$ of patients are now treated with endovascular repair. ${ }^{8}$ EVAR is not only becoming the first choice of treatment for patients with infrarenal AAAs, but is also gaining traction for the management of increasingly challenging anatomy. Interestingly, the survival benefit in terms of 30-day operative mortality for EVAR compared with open repair remains most convincing in patients with few or no comorbidities. ${ }^{7}$ As indications expand and devices evolve, ongoing research is critical to ensure effective and evidence-based utilization of this promising technology.

\section{Acknowledgments}

The authors thank Thomas Curran M.D., Beth Israel Deaconess Medical Centre, Boston, MA, USA for his valuable editorial review of this manuscript.

\section{References}

1. Volodos NL, Shekhanin VE, Karpovich IP, Troian VI, Gur'ev IA. A self-fixing synthetic blood vessel endoprosthesis [Russian]. Vestn. Khir. Im. I. I. Grek. 1986; 137:123-125. [PubMed: 3824776]

2. Volodos NL. Historical perspective: the first steps in endovascular aortic repair: how it all began. J. Endovasc. Ther. 2013; 20(Suppl. 1):13-123. [PubMed: 23391075]

3. Parodi JC, Palmaz JC, Barone HD. Transfemoral intraluminal graft implantation for abdominal aortic aneurysms. Ann. Vasc. Surg. 1991; 5:491-499. [PubMed: 1837729]

4. Eisenack M, Umscheid T, Tessarek J, Torsello GF, Torsello GB. Percutaneous endovascular aortic aneurysm repair: a prospective evaluation of safety, efficiency, and risk factors. J. Endovasc. Ther. 2009; 16:708-713. [PubMed: 19995109]

5. Drury D, Michaels JA, Jones L, Ayiku L. Systematic review of recent evidence for the safety and efficacy of elective endovascular repair in the management of infrarenal abdominal aortic aneurysm. Br. J. Surg. 2005; 92:937-946. [PubMed: 16034817]

6. Nowygrod R, et al. Trends, complications, and mortality in peripheral vascular surgery. J. Vasc. Surg. 2006; 43:205-216. [PubMed: 16476588] 
7. Brown LC, Greenhalgh RM, Howell S, Powell JT, Thompson SG. Patient fitness and survival after abdominal aortic aneurysm repair in patients from the UK EVAR trials. Br. J. Surg. 2007; 94:709716. [PubMed: 17514695]

8. Schermerhorn ML, et al. Changes in abdominal aortic aneurysm rupture and short-term mortality, 1995-2008: a retrospective observational study. Ann. Surg. 2012; 256:651-658. [PubMed: 22964737]

9. Cornuz J, Sidoti Pinto C, Tevaearai H, Egger M. Risk factors for asymptomatic abdominal aortic aneurysm: systematic review and meta-analysis of population-based screening studies. Eur. J. Public Health. 2004; 14:343-349. [PubMed: 15542867]

10. Lederle FA, et al. The aneurysm detection and management study screening program: validation cohort and final results. Aneurysm Detection and Management Veterans Affairs Cooperative Study Investigators. Arch. Intern. Med. 2000; 160:1425-1430. [PubMed: 10826454]

11. Powell JT, Greenhalgh RM. Clinical practice. Small abdominal aortic aneurysms. N. Engl. J. Med. 2003; 348:1895-1901. [PubMed: 12736283]

12. Lo RC, et al. Gender differences in abdominal aortic aneurysm presentation, repair, and mortality in the Vascular Study Group of New England. J. Vasc. Surg. 2013; 57:1261-1268. [PubMed: 23384493]

13. Mofidi R, et al. Influence of sex on expansion rate of abdominal aortic aneurysms. Br. J. Surg. 2007; 94:310-314. [PubMed: 17262754]

14. Egorova NN, et al. Effect of gender on long-term survival after abdominal aortic aneurysm repair based on results from the Medicare national database. J. Vasc. Surg. 2011; 54:1-12. [PubMed: 21498023]

15. Semmens JB, Norman PE, Lawrence-Brown MM, Bass AJ, Holman CD. Population-based record linkage study of the incidence of abdominal aortic aneurysm in Western Australia in 1985-1994. Br. J. Surg. 1998; 85:648-652. [PubMed: 9635813]

16. Fowkes FG, Macintyre CC, Ruckley CV. Increasing incidence of aortic aneurysms in England and Wales. BMJ. 1989; 298:33-35. [PubMed: 2492850]

17. Filipovic M, et al. Trends in mortality and hospital admission rates for abdominal aortic aneurysm in England and Wales, 1979-1999. Br. J. Surg. 2005; 92:968-975. [PubMed: 16034842]

18. Acosta $S$, et al. Increasing incidence of ruptured abdominal aortic aneurysm: a population-based study. J. Vasc. Surg. 2006; 44:237-243. [PubMed: 16890847]

19. Sandiford P, Mosquera D, Bramley D. Trends in incidence and mortality from abdominal aortic aneurysm in New Zealand. Br. J. Surg. 2011; 98:645-651. [PubMed: 21381003]

20. Norman PE, Spilsbury K, Semmens JB. Falling rates of hospitalization and mortality from abdominal aortic aneurysms in Australia. J. Vasc. Surg. 2011; 53:274-277. [PubMed: 21055899]

21. Giles KA, et al. Decrease in total aneurysm-related deaths in the era of endovascular aneurysm repair. J. Vasc. Surg. 2009; 49:543-550. [PubMed: 19135843]

22. Anjum A, Powell JT. Is the incidence of abdominal aortic aneurysm declining in the $21^{\text {st }}$ century? Mortality and hospital admissions for England \& Wales and Scotland. Eur. J. Vasc. Endovasc. Surg. 2012; 43:161-166. [PubMed: 22178251]

23. Anjum A, von Allman R, Greenhalgh R, Powell JT. Explaining the decrease in mortality from abdominal aortic aneurysm rupture. Br. J. Surg. 2012; 99:637-645. [PubMed: 22473277]

24. Wilmink AB, Forshaw M, Quick CR, Hubbard CS, Day NE. Accuracy of serial screening for abdominal aortic aneurysms by ultrasound. J. Med. Screen. 2002; 9:125-127. [PubMed: 12370324]

25. Rudarakanchana N, Powell JT. Advances in imaging and surveillance of AAA: when, how, how often? Prog. Cardiovasc. Dis. 2013; 56:7-12. [PubMed: 23993233]

26. Moll FL, et al. Management of abdominal aortic aneurysms clinical practice guidelines of the European society for vascular surgery. Eur. J. Vasc. Endovasc. Surg. 2011; 41(Suppl. 1):S1-S58. [PubMed: 21215940]

27. Beeman BR, et al. Duplex ultrasound factors predicting persistent type II endoleak and increasing AAA sac diameter after EVAR. J. Vasc. Surg. 2010; 52:1147-1152. [PubMed: 20691559] 
28. Iezzi R, et al. Contrast-enhanced ultrasound versus color duplex ultrasound imaging in the followup of patients after endovascular abdominal aortic aneurysm repair. J. Vasc. Surg. 2009; 49:552560. [PubMed: 19135839]

29. Ten Bosch JA, et al. Contrast-enhanced ultrasound versus computed tomographic angiography for surveillance of endovascular abdominal aortic aneurysm repair. J. Vasc. Interv. Radiol. 2010; 21:638-643. [PubMed: 20363153]

30. Wilson SR, Greenbaum LD, Goldberg BB. Contrast-enhanced ultrasound: what is the evidence and what are the obstacles? AJR1 Am. J. Roentgenol. 2009; 193:55-60.

31. Sun Z. Helical CT angiography of fenestrated stent grafting of abdominal aortic aneurysms. Biomed. Imaging. Interv. J. 2009; 5:e3. [PubMed: 21611029]

32. Rydberg J, et al. Endovascular repair of abdominal aortic aneurysms: assessment with multislice $\mathrm{C}$ T. AJR Am. J. Roentgenol. 2001; 177:607-614. [PubMed: 11517055]

33. Sun Z. Multislice CT angiography in abdominal aortic aneurysm treated with endovascular stent grafts: evaluation of 2D and 3D visualisations. Biomed. Imaging Interv. J. 2007; 3:e20. [PubMed: 21614294]

34. Sun ZH. Abdominal aortic aneurysm: treatment options, image visualizations and follow-up procedures. J. Geriatr. Cardiol. 2012; 9:49-60. [PubMed: 22783323]

35. van Keulen JW, Moll FL, van Herwaarden JA. Tips and techniques for optimal stent graft placement in angulated aneurysm necks. J. Vasc. Surg. 2010; 52:1081-1086. [PubMed: 20478684]

36. van Keulen JW, van Prehn J, Prokop M, Moll FL, van Herwaarden JA. Dynamics of the aorta before and after endovascular aneurysm repair: a systematic review. Eur. J. Vasc. Endovasc. Surg. 2009; 38:586-596. [PubMed: 19648032]

37. Neschis DG, et al. The role of magnetic resonance angiography for endoprosthetic design. J. Vasc. Surg. 2001; 33:488-494. [PubMed: 11241117]

38. Upchurch, GR.; Criado, E., editors. Aortic Aneurysms: Pathogenesis and Treatment. Humana Press; 2009.

39. Habets J, et al. Magnetic resonance imaging is more sensitive than computed tomography angiography for the detection of endoleaks after endovascular abdominal aortic aneurysm repair: a systematic review. Eur. J. Vasc. Endovasc. Surg. 2013; 45:340-350. [PubMed: 23403221]

40. Korosec FR, Frayne R, Grist TM, Mistretta CA. Time-resolved contrast-enhanced 3D MR angiography. Magn. Reson. Med. 1996; 36:345-351. [PubMed: 8875403]

41. Cohen EI, et al. Time-resolved MR angiography for the classification of endoleaks after endovascular aneurysm repair. J. Magn. Reson. Imaging. 2008; 27:500-503. [PubMed: 18307209]

42. Lookstein RA, Goldman J, Pukin L, Marin ML. Time-resolved magnetic resonance angiography as a noninvasive method to characterize endoleaks: initial results compared with conventional angiography. J. Vasc. Surg. 2004; 39:27-33. [PubMed: 14718808]

43. Lee JT, White RA. Basics of intravascular ultrasound: an essential tool for the endovascular surgeon. Semin. Vasc. Surg. 2004; 17:110-118. [PubMed: 15185176]

44. Marrocco CJ, et al. Intravascular ultrasound. Semin. Vasc. Surg. 2012; 25:144-152. [PubMed: 23062494]

45. Prinssen $\mathrm{M}$, et al. A randomized trial comparing conventional and endovascular repair of abdominal aortic aneurysms. N. Engl. J. Med. 2004; 351:1607-1618. [PubMed: 15483279]

46. Blankensteijn JD, et al. Two-year outcomes after conventional or endovascular repair of abdominal aortic aneurysms. N. Engl. J. Med. 2005; 352:2398-2405. [PubMed: 15944424]

47. De Bruin JL, et al. Long-term outcome of open or endovascular repair of abdominal aortic aneurysm. N. Engl. J. Med. 2010; 362:1881-1889. [PubMed: 20484396]

48. Greenhalgh RM, et al. Comparison of endovascular aneurysm repair with open repair in patients with abdominal aortic aneurysm (EVAR trial 1), 30-day operative mortality results: randomised controlled trial. Lancet. 2004; 364:843-848. [PubMed: 15351191]

49. EVAR trial participants. Endovascular aneurysm repair versus open repair in patients with abdominal aortic aneurysm (EVAR trial 1): randomised controlled trial. Lancet. 2005; 365:2179_ 2186. [PubMed: 15978925] 
50. United Kingdom EVAR Trial Investigators. Endovascular versus open repair of abdominal aortic aneurysm. N. Engl. J. Med. 2010; 362:1863-1871. [PubMed: 20382983]

51. EVAR trial participants. Endovascular aneurysm repair and outcome in patients unfit for open repair of abdominal aortic aneurysm (EVAR trial 2): randomised controlled trial. Lancet. 2005; 365:2187-2192. [PubMed: 15978926]

52. Brown LC, et al. The UK EndoVascular Aneurysm Repair (EVAR) trials: randomised trials of EVAR versus standard therapy. Health Technol. Assess. 2012; 16:1-218. [PubMed: 22381040]

53. United Kingdom EVAR Trial Investigators. Endovascular repair of aortic aneurysm in patients physically ineligible for open repair. N. Engl. J. Med. 2010; 362:1872-1880. [PubMed: 20382982]

54. Lederle FA, et al. Outcomes following endovascular vs open repair of abdominal aortic aneurysm: a randomized trial. JAMA. 2009; 302:1535-1542. [PubMed: 19826022]

55. Lederle FA, et al. Long-term comparison of endovascular and open repair of abdominal aortic aneurysm. N. Engl. J. Med. 2012; 367:1988-1997. [PubMed: 23171095]

56. Becquemin JP, et al. A randomized controlled trial of endovascular aneurysm repair versus open surgery for abdominal aortic aneurysms in low- to moderate-risk patients. J. Vasc. Surg. 2011; 53:1167-1173. [PubMed: 21276681]

57. Schermerhorn ML, et al. Endovascular vs. open repair of abdominal aortic aneurysms in the Medicare population. N. Engl. J. Med. 2008; 358:464-474. [PubMed: 18234751]

58. Schanzer A, et al. Predictors of abdominal aortic aneurysm sac enlargement after endovascular repair. Circulation. 2011; 123:2848-2855. [PubMed: 21478500]

59. Fillinger M. Letter by Fillinger regarding article, "Predictors of abdominal aortic aneurysm sac enlargement after endovascular repair”. Circulation. 2012; 125:e341. [PubMed: 22311891]

60. US Food and Drug Administration. Medical devices: device approvals and clearances. 2013. [online], http://www.fda.gov/MedicalDevices/ProductsandMedicalProcedures/ DeviceApprovalsandClearances/default.htm

61. Cao P, et al. Comparison of surveillance versus aortic endografting for small aneurysm repair (CAESAR): results from a randomised trial. Eur. J. Vasc. Endovasc. Surg. 2011; 41:13-25. [PubMed: 20869890]

62. Donas KP, Kafetzakis A, Umsheid T, Tessarek J, Torsello G. Vascular endostapling: new concept for endovascular fixation of aortic stent-grafts. J. Endovasc. Ther. 2008; 15:499-503. [PubMed: 18840048]

63. Donas KP, Torsello G. Midterm results of the Anson Refix endostapling fixation system for aortic stent-grafts. J. Endovasc. Ther. 2010; 17:320-323. [PubMed: 20557169]

64. Avci M, et al. The use of endoanchors in repair EVAR cases to improve proximal endograft fixation. J. Cardiovasc. Surg. (Torino). 2012; 53:419-426.

65. Taylor SM, Mills JL, Fujitani RM. The juxtarenal abdominal aortic aneurysm. A more common problem than previously realized? Arch. Surg. 1994; 129:734-737. [PubMed: 8024454]

66. Jongkind V, et al. Juxtarenal aortic aneurysm repair. J. Vasc. Surg. 2010; 52:760-767. [PubMed: 20382492]

67. Faruqi RM, et al. Endovascular repair of abdominal aortic aneurysm using a pararenal fenestrated stent-graft. J. Endovasc. Surg. 1999; 6:354-358. [PubMed: 10893139]

68. Browne TF, et al. A fenestrated covered suprarenal aortic stent. Eur. J. Vasc. Endovasc. Surg. 1999; 18:445-449. [PubMed: 10610834]

69. Anderson JL, Berce M, Hartley DE. Endoluminal aortic grafting with renal and superior mesenteric artery incorporation by graft fenestration. J. Endovasc. Ther. 2001; 8:3-15. [PubMed: 11220465]

70. Nypaver TJ, et al. Repair of pararenal abdominal aortic aneurysms. An analysis of operative management. Arch. Surg. 1993; 128:803-811. [PubMed: 8317963]

71. Sarac TP, et al. Contemporary results of juxtarenal aneurysm repair. J. Vasc. Surg. 2002; 36:11041111. [PubMed: 12469040]

72. Katsargyris A, Oikonomou K, Klonaris C, Töpel I, Verhoeven EL. Comparison of outcomes with open, fenestrated, and chimney graft repair of juxtarenal aneurysms: are we ready for a paradigm shift? J. Endovasc. Ther. 2013; 20:159-169. [PubMed: 23581756] 
73. Scurr JR, et al. Fenestrated endovascular repair for juxtarenal aortic aneurysm. Br. J. Surg. 2008; 95:326-332. [PubMed: 17932878]

74. Bicknell CD, et al. Treatment of complex aneurysmal disease with fenestrated and branched stent grafts. Eur. J. Vasc. Endovasc. Surg. 2009; 37:175-181. [PubMed: 19046650]

75. O'Neill S, et al. A prospective analysis of fenestrated endovascular grafting: intermediate-term outcomes. Eur. J. Vasc. Endovasc. Surg. 2006; 32:115-123. [PubMed: 16580236]

76. Mastracci TM, Greenberg RK, Eagleton MJ, Hernandex AV. Durability of branches in branched and fenestrated endografts. J. Vasc. Surg. 2013; 57:926-933. [PubMed: 23433817]

77. Amiot S, et al. Fenestrated endovascular grafting: the French multicentre experience. Eur. J. Vasc. Endovasc. Surg. 2010; 39:537-544. [PubMed: 20093051]

78. Verhoeven EL, et al. Fenestrated stent grafting for short-necked and juxtarenal abdominal aortic aneurysm: an 8-year single-centre experience. Eur. J. Vasc. Endovasc. Surg. 2010; 39:529-536. [PubMed: 20202868]

79. Linsen MA, Jongkind V, Nio D, Hoksbergen AW, Wisselink W. Pararenal aortic aneurysm repair using fenestrated endografts. J. Vasc. Surg. 2012; 56:238-246. [PubMed: 22264696]

80. Cross J, et al. Indications for fenestrated endovascular aneurysm repair. Br. J. Surg. 2012; 99:217224. [PubMed: 22222802]

81. Ohrlander T, et al. The chimney graft: a technique for preserving or rescuing aortic branch vessels in stent-graft sealing zones. J. Endovasc. Ther. 2008; 15:427-432. [PubMed: 18729550]

82. Patel RP, Katsargyris A, Verhoeven EL, Adam DJ, Hardman JA. Endovascular aortic aneurysm repair with chimney and snorkel grafts: indications, techniques and results. Cardiovasc. Intervent. Radiol. 2013; 36:1443-1451. [PubMed: 23674274]

83. Criado FJ. Chimney grafts and bare stents: aortic branch preservation revisited. J. Endovasc. Ther. 2007; 14:823-824. [PubMed: 18052599]

84. Tolenaar JL, et al. The chimney graft, a systematic review. Ann. Vasc. Surg. 2012; 26:1030-1038. [PubMed: 22498342]

85. Tolenaar JL, Zandvoort HJ, Moll FL, van Herwaarden JA. Technical considerations and results of chimney grafts for the treatment of juxtarenal aneurysms. J. Vasc. Surg. 2013; 58:607-615. [PubMed: 23684412]

86. Bruen KJ, Feezor RJ, Daniels MJ, Beck AW, Lee WA. Endovascular chimney technique versus open repair of juxtarenal and suprarenal aneurysms. J. Vasc. Surg. 2011; 53:895-904. [PubMed: 21211934]

87. Allaqaband S, Kumar A, Bajwa T. A novel technique of aortomonoiliac AAA repair in patients with a single patent iliac artery: a "stent-graft sandwich". J. Endovasc. Ther. 2004; 11:550-552. [PubMed: 15482028]

88. Lobato AC. Sandwich technique for aortoiliac aneurysms extending to the internal iliac artery or isolated common/internal iliac artery aneurysms: a new endovascular approach to preserve pelvic circulation. J. Endovasc. Ther. 2011; 18:106-111. [PubMed: 21314358]

89. Kolvenbach RR, Yoshida R, Pinter L, Zhu Y, Lin F. Urgent endovascular treatment of thoracoabdominal aneurysms using a sandwich technique and chimney grafts-a technical description. Eur. J. Vasc. Endovasc. Surg. 2011; 41:54-60. [PubMed: 20961775]

90. Tolenaar JL, Zandvoort HJ, Hazenberg CE, Moll FL, van Herwaarden JA. The double twochimney technique for complete renovisceral revascularization in a suprarenal aneurysm. J. Vasc. Surg. 2013; 58:478-481. [PubMed: 23402874]

91. Chuter TA, Hiramoto JS, Park KH, Reilly LM. The transition from custom-made to standardized multibranched thoracoabdominal aortic stent grafts. J. Vasc. Surg. 2011; 54:660-667. [PubMed: 21788114]

92. Kitagawa A, Greenberg RK, Eagleton MJ, Mastracci TM. Zenith p-branch standard fenestrated endovascular graft for juxtarenal abdominal aortic aneurysms. J. Vasc. Surg. 2013; 58:291-300. [PubMed: 23611709]

93. Resch TA, et al. Development of off-the-shelf stent grafts for juxtarenal abdominal aortic aneurysms. Eur. J. Vasc. Endovasc. Surg. 2012; 43:655-660. [PubMed: 22342691]

94. Henry M, et al. Treatment of renal artery aneurysm with the multilayer stent. J. Endovasc. Ther. 2008; 15:231-236. [PubMed: 18426265] 
95. Zhang YX, Lu QS, Jing ZP. Multilayer stents, a new progress in the endovascular treatment of aneurysms. Chin. Med. J. (Engl.). 2013; 126:536-541. [PubMed: 23422121]

96. Sfyroeras GS, et al. Flow-diverting stents for the treatment of arterial aneurysms. J. Vasc. Surg. 2012; 56:839-846. [PubMed: 22840737]

97. Donayre CE, et al. Initial clinical experience with a sac-anchoring endoprosthesis for aortic aneurysm repair. J. Vasc. Surg. 2011; 53:574-582. [PubMed: 21211931]

98. Krievins DK, et al. EVAR using the Nellix Sac-anchoring endoprosthesis: treatment of favourable and adverse anatomy. Eur. J. Vasc. Endovasc. Surg. 2011; 42:38-46. [PubMed: 21497521]

99. Chuter TA. Stent-graft design: the good, the bad and the ugly. Cardiovasc. Surg. 2002; 10:7-13. [PubMed: 11790568]

100. Mehta M, et al. One-year outcomes from an international study of the Ovation Abdominal Stent Graft System for endovascular aneurysm repair. J. Vasc. Surg.

101. Perdikides T, et al. Primary endoanchoring in the endovascular repair of abdominal aortic aneurysms with an unfavorable neck. J. Endovasc. Ther. 2012; 19:707-715. [PubMed: 23210865]

102. Kasprzak P, Pfister K, Janotta M, Kopp R. EndoAnchor placement in thoracic and thoracoabdominal stent-grafts to repair complications of nonalignment. J. Endovasc. Ther. 2013:471-480. [PubMed: 23914854]

103. Endologix. AFX ${ }^{\mathrm{TM}}$ endovascular AAA system (bifurcated stent graft models and accessory models): instructions for use. 2010. [online], http://www.endologix.com/pdf/AFX \%20StentGraft\&Access\%20English\%20C00541RevA\%20-\%20PW\%20protected.pdf 


\section{Key points}

- Endovascular aneurysm repair (EVAR), rather than open repair, is currently the treatment of choice for most patients with an anatomically suitable infrarenal abdominal aortic aneurysm (AAA)

- Clinical evidence-based research shows a lower perioperative morbidity and mortality, and similar long-term survival, for EVAR compared with open repair of suitable infrarenal AAAs

- The indications for endovascular management of AAA are expanding to include increasingly complex and anatomically challenging aneurysms

- Challenging anatomy might require the use of fenestrated and branched stent grafts, chimney grafts, or the sandwich technique

- Future directions for stent grafts include fenestrated and branched off-the-shelf stent grafts, multilayer stents, endoanchor systems, and sac-anchoring endoprostheses

- Stent graft technology for infrarenal AAA continues to evolve, with profile downsizing, optimization of sealing and fixation, and the use of fabrics with reduced porosity 


\section{Review criteria}

Focused on endovascular treatment of aneurysmal aortic disease, a search for original articles, reviews, and metaanalyses was performed using Pubmed and MEDLINE. Search phrases used were "EVAR", "endovascular repair", or "aortic aneurysm", alone or in combination with one of the following words: "mortality", "gender", "imaging", "versus open", "stent graft", "indications", "juxtarenal”, "suprarenal”, and "outcome”. Most articles identified were full-text papers written in English. No time limits were set. The reference lists of identified articles were also searched for additional material. 

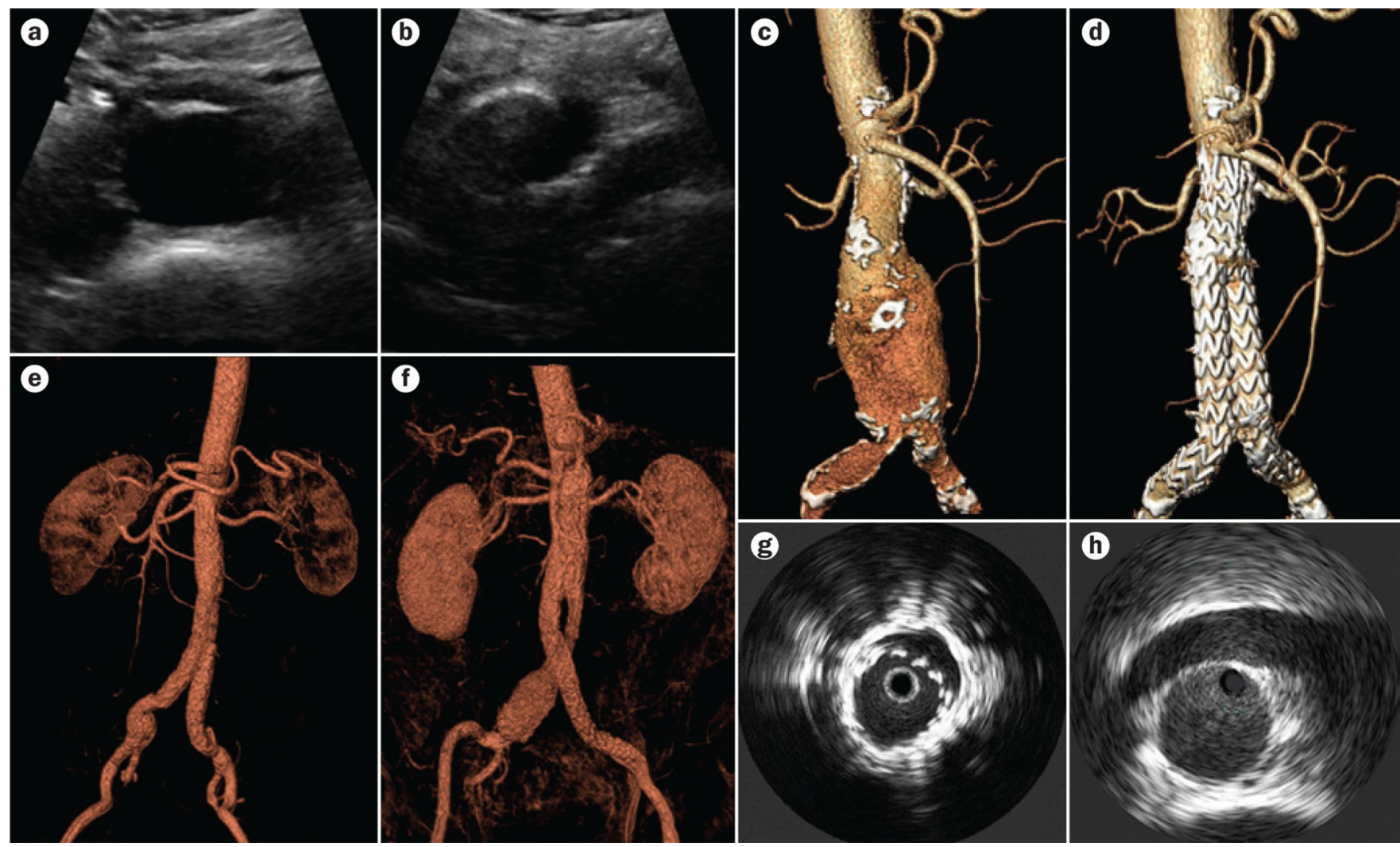

Figure 1.

Imaging modalities used in the management of patients with AAA. a | Ultrasonography showing a transverse view of the distal aorta showing the diameter of the vessel. $\mathbf{b}$ | Ultrasonography showing a transverse view showing the aortic bifurcation; left and right iliac artery. $\mathbf{c} \mid$ Preoperative and $\mathbf{d} \mid$ postoperative 3D CTA reconstruction for a patient with AAA. e,f | Two postoperative 3D MRA reconstructions for a patient with AAA. g | IVUS demonstrating incomplete expansion of a stent graft in an AAA. Reprinted from Lee, J. T. \& White, R. A. Basics of intravascular ultrasound: an essential tool for the endovascular surgeon. Semin. Vasc. Surg. 17, 110-118, Copyright 2004, with permission from Elsevier. h | IVUS demonstrating standard measurement of the aorta at the level of the renal arteries. Reprinted from Marrocco, C. J. et al. Intravascular ultrasound. Semin. Vasc. Surg. 25, 144 152, Copyright 2012, with permission from Elsevier. Abbreviations: AAA, abdominal aortic aneurysm; CTA, computed tomography angiography; IVUS, intravascular ultrasound; MRA, magnetic resonance angiography. 


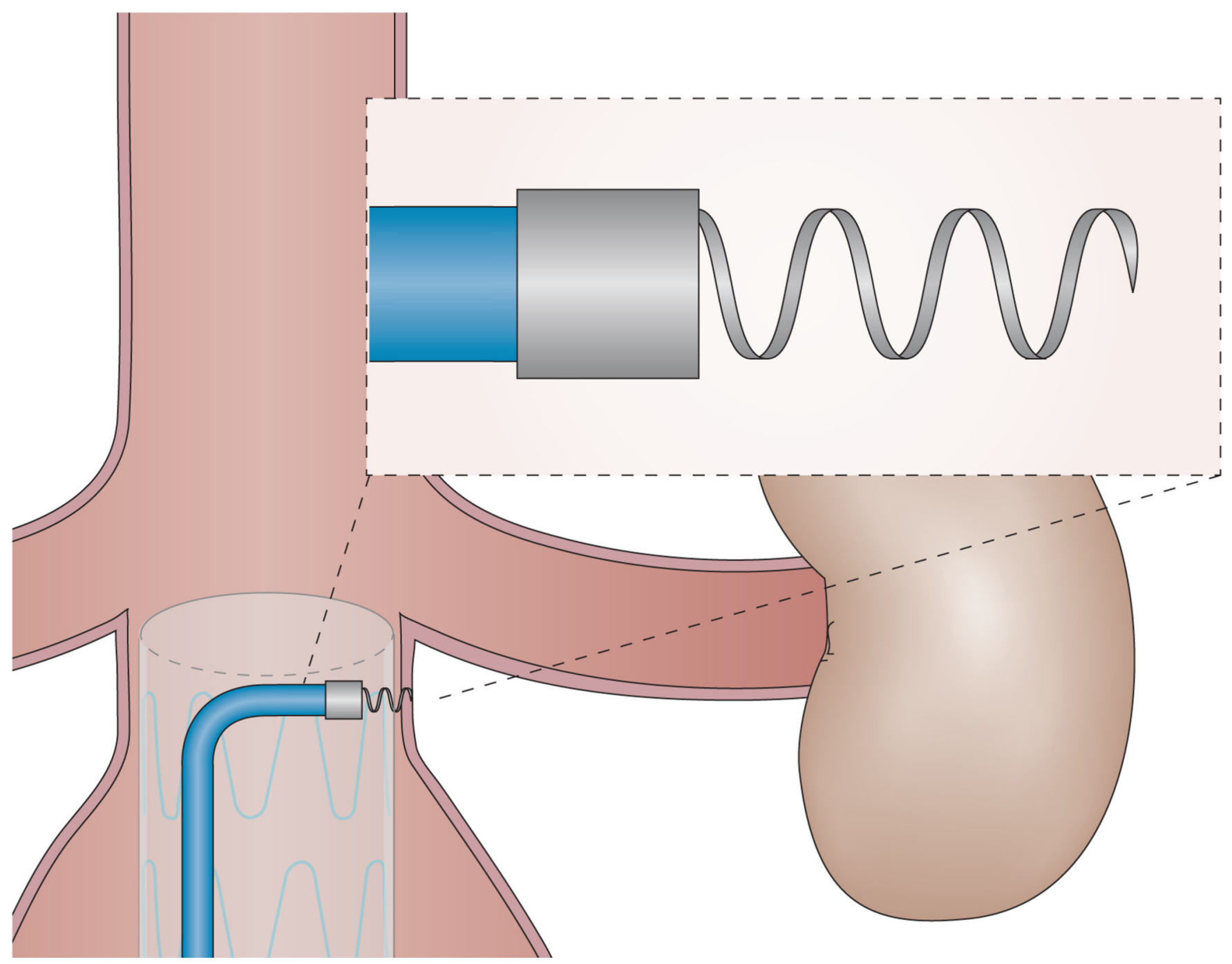

Figure 2.

The endoanchor system, which can be used for transmural fixation of an aortic stent graft to the aortic wall at its landing zones. 


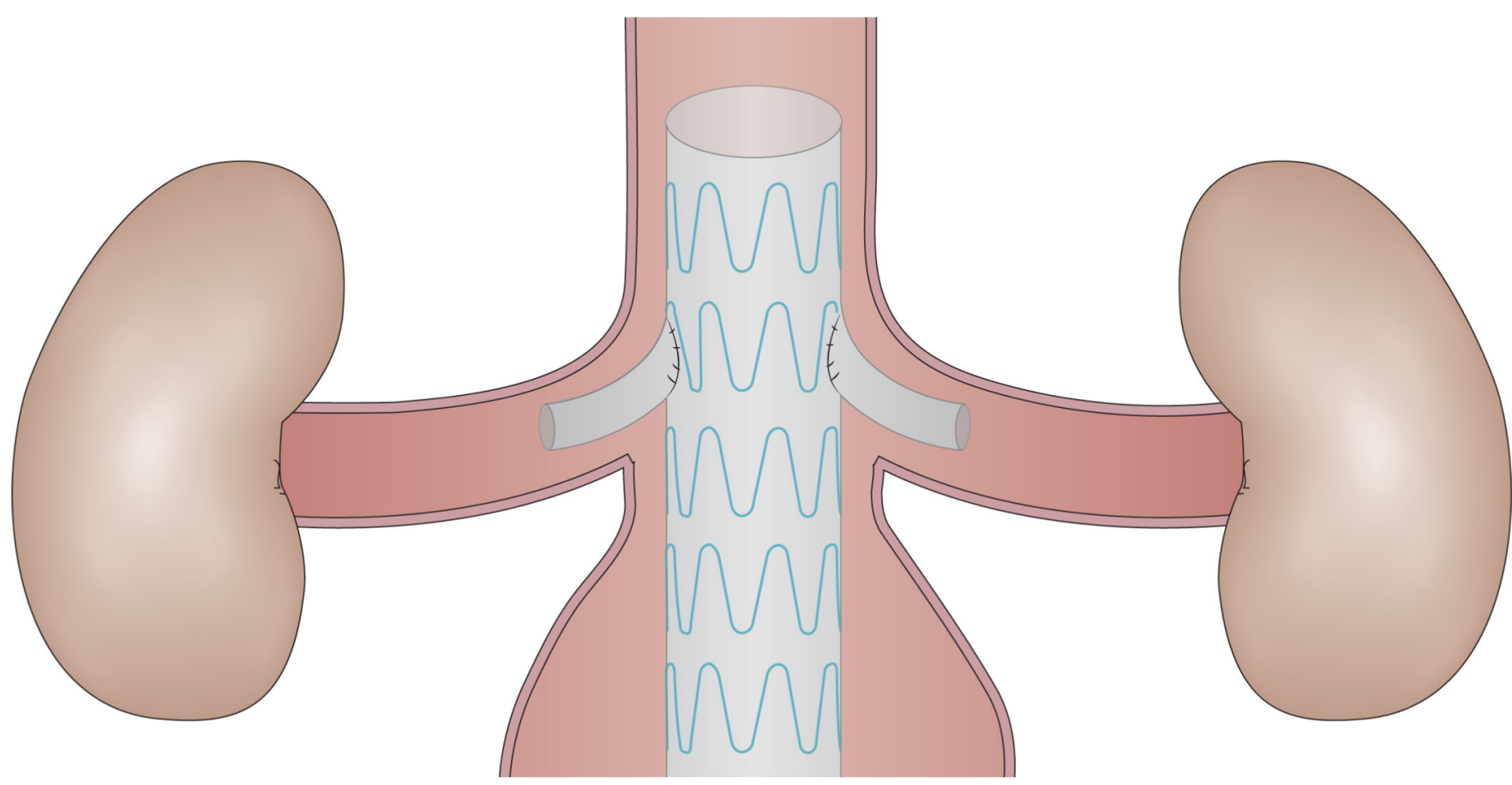

Figure 3.

A fenestrated stent graft. This type of stent graft overcomes the problem of an insufficient infrarenal neck for stent graft implantation in patients with juxtarenal or suprarenal aortic aneurysms, whilst preserving renal and/or mesenteric perfusion. 


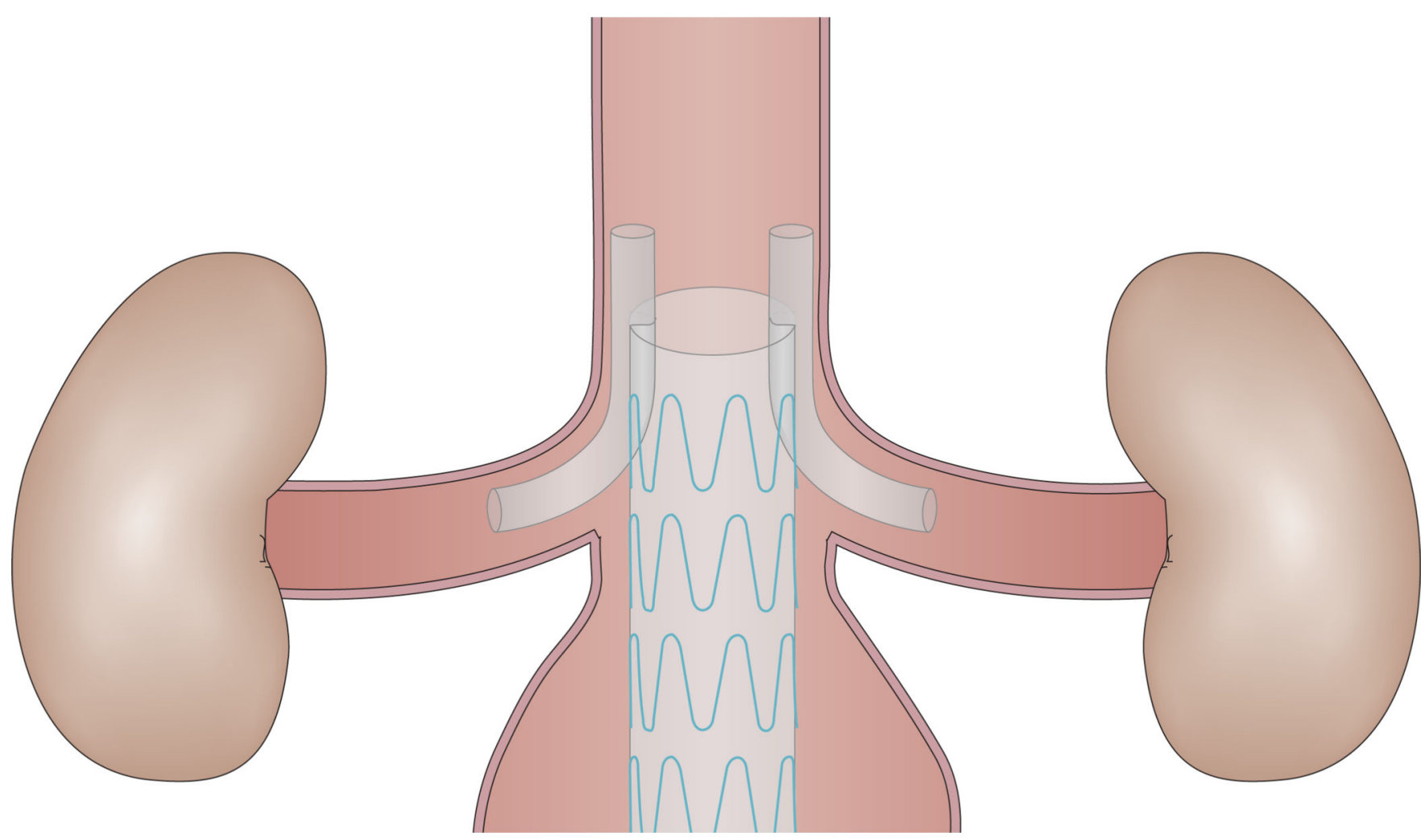

Figure 4.

A chimney graft. Similarly to the fenestrated stent graft, the chimney graft preserves the renal and/or mesenteric perfusion. Notably, however, the chimney graft is cheaper than the fenestrated stent graft, and has broader applicability for emergent cases because customization is not needed. 

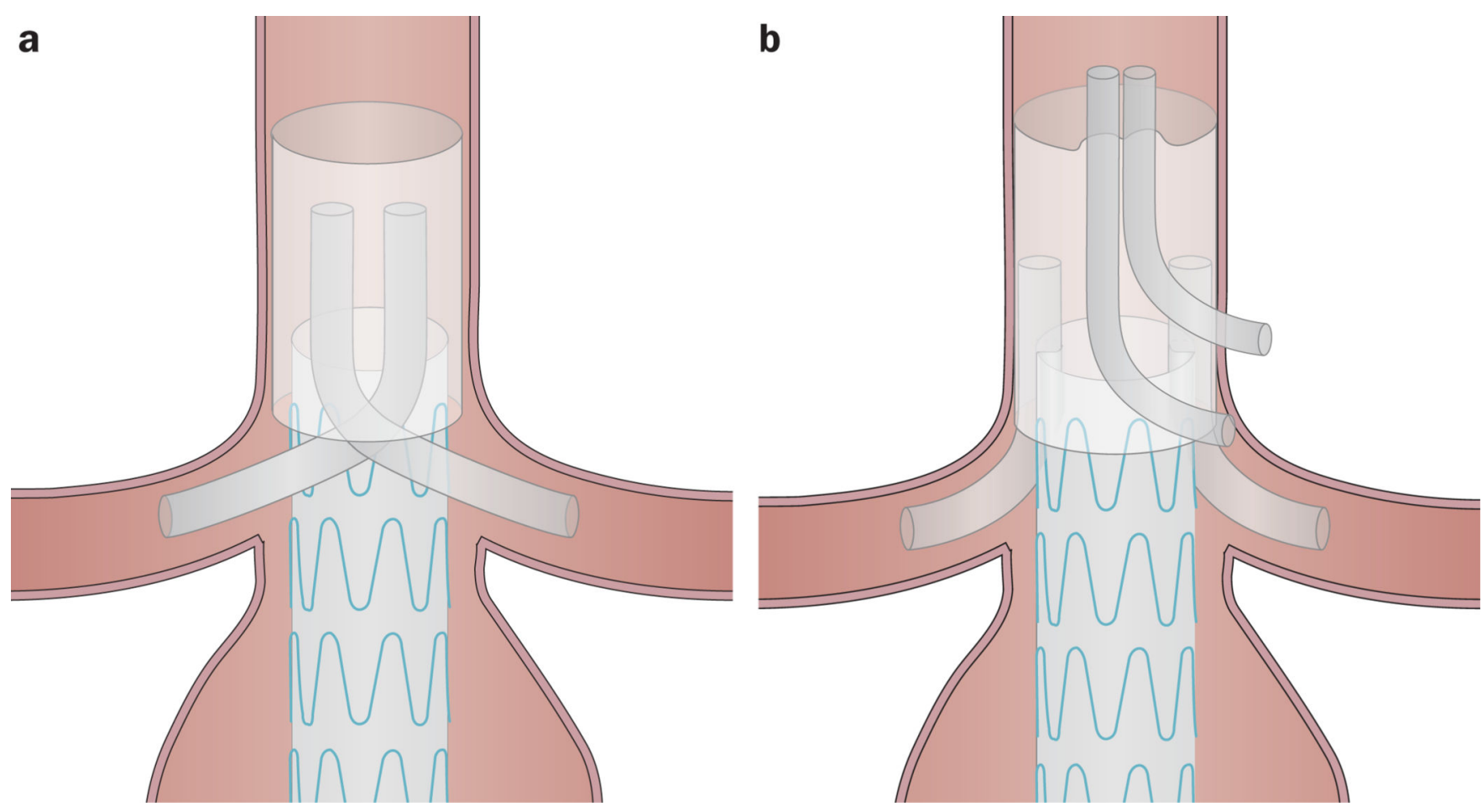

Figure 5.

Endovascular aneurysm repair strategies that enable the revascularization of up to four aortic side branches. a In the sandwich technique, which can be used in patients not deemed suitable for conventional endovascular aneurysm repair, stents placed in the aortic branches are 'sandwiched' between two aortic stent grafts. $\mathbf{b} \mid$ The double two-chimney approach is an alternative to the sandwich technique. Of note, long-term outcomes are not yet available for the sandwich technique or the double two-chimney technique, and both techniques have only been used in situations not listed in the manufacturers' instructions for use. 


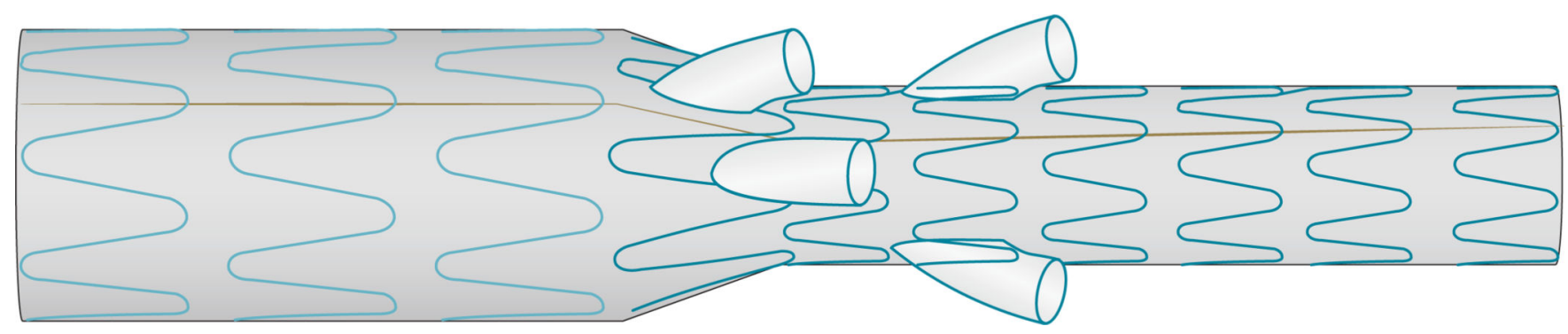

Figure 6.

An off-the-shelf branched stent graft. These 'ready to go' stent grafts have been developed for treatment of patients with complex abdominal aortic aneurysm in the acute setting, as stent customization can lead to substantial treatment delay. 
Buck et al.

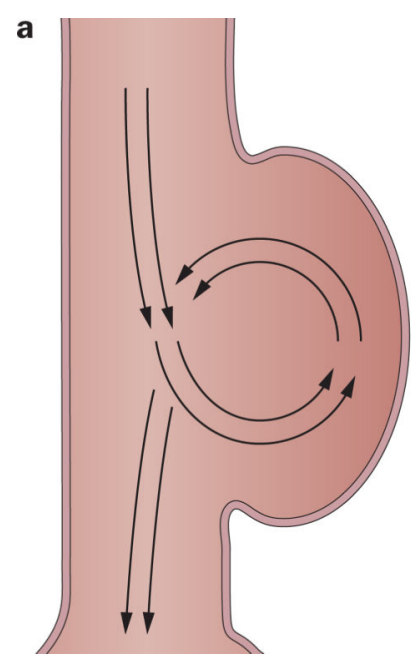

b

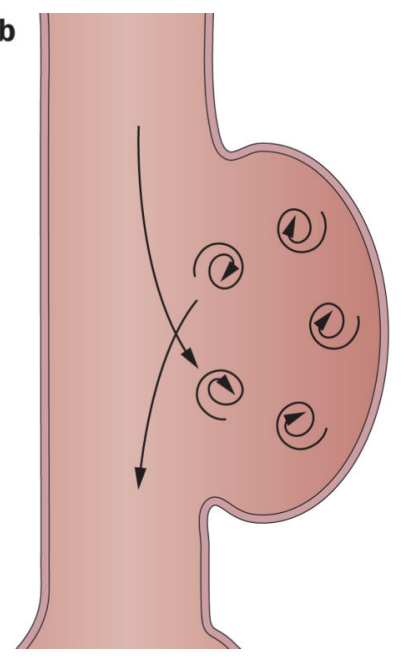

c

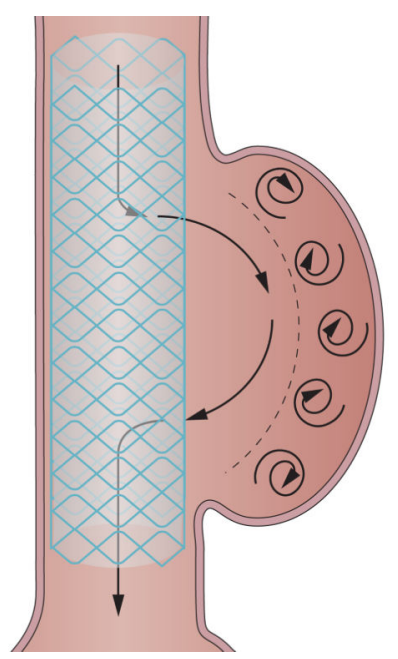

Page 27

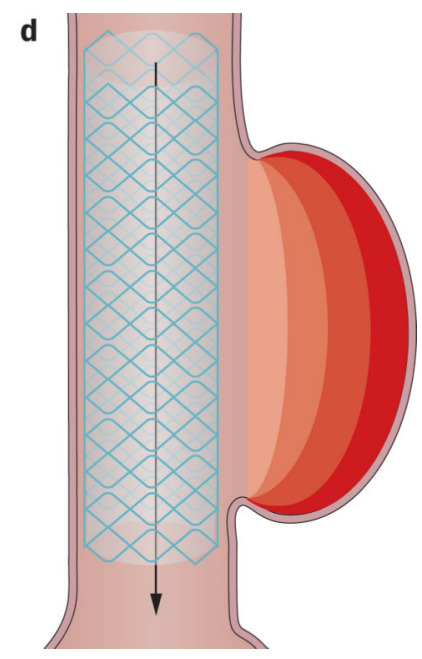

Figure 7.

The multilayer stent graft. a | Blood flow through a saccular aortic aneurysm. b |A saccular aortic aneurysm with an increased flow velocity. c | A saccular aortic aneurysm treated with a multilayer stent, which decreases the flow velocity into the aneurysm. d | The blood flow though the multilayer stent as the aortic aneurysm is thrombosed. 


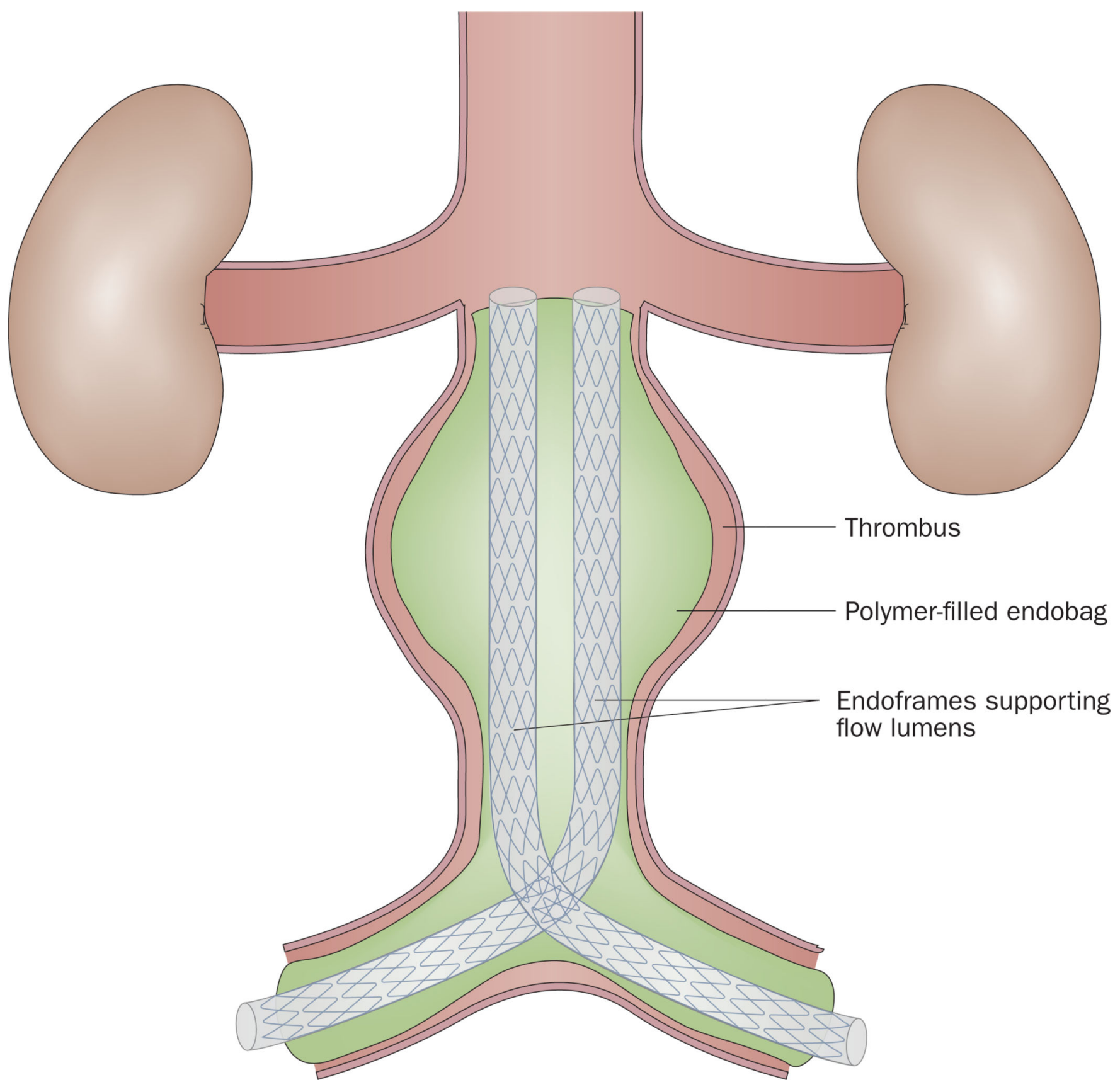

Figure 8.

The sac-anchoring system, consisting of two femorally inserted stent grafts with polymerfilled endobags on the outside of the stent. The polymer-filled endobags enlarge to a pressure preset to support the stents within the aneurysm sac. The technology eliminates the endoleak space via obliteration of the aortic aneurysm sac. 


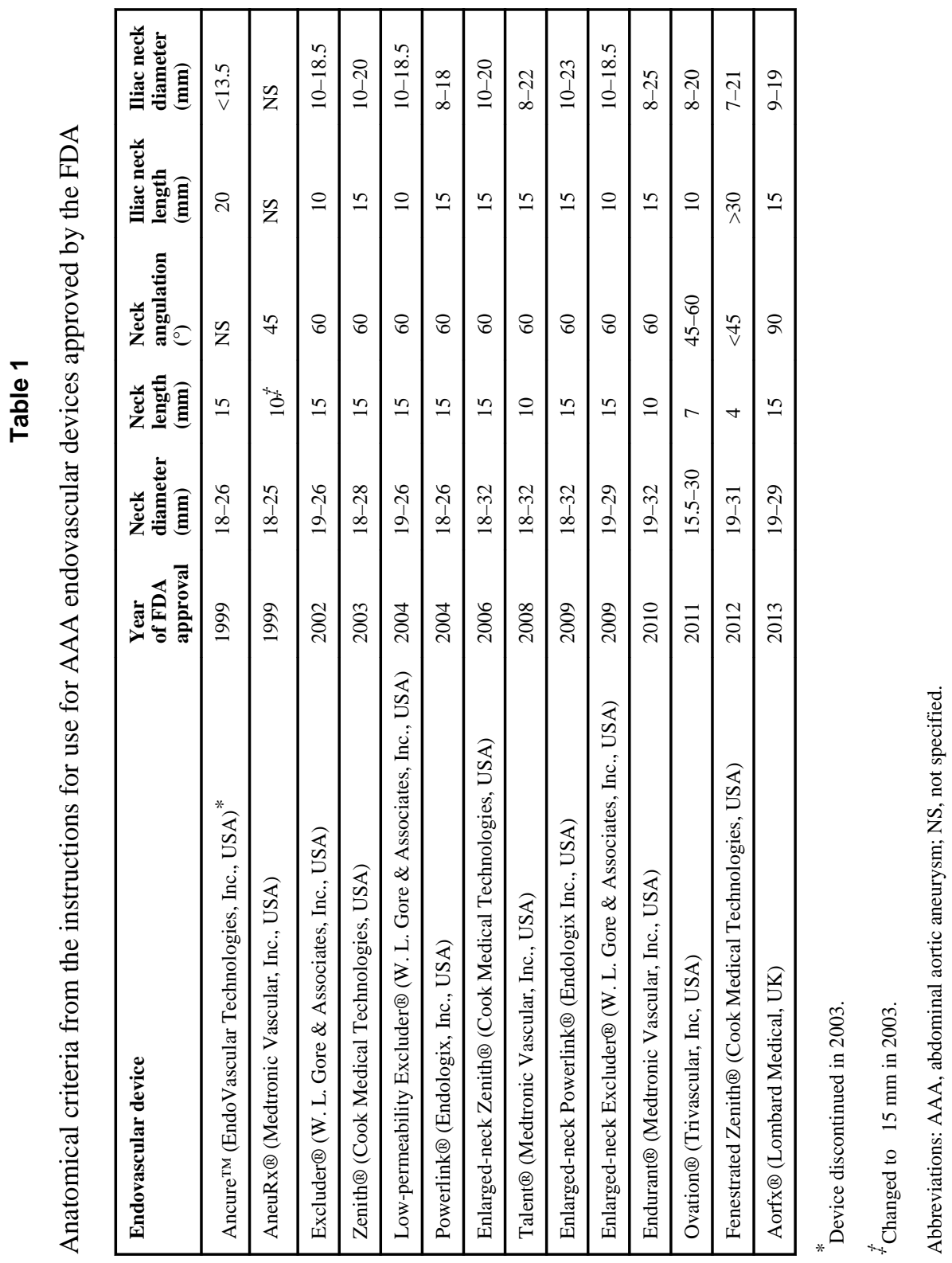

Nat Rev Cardiol. Author manuscript; available in PMC 2015 February 01. 